\title{
Toward a surveillance society? Privacy and surveillance in the Bundestag debates
}

\author{
Iana Gein ${ }^{1}$
}

\begin{abstract}
This study highlights the dominant frames related to privacy and surveillance in the Bundestag debates in the period between 2014 and 2017. By performing an inductive framing analysis of the Parliamentary protocols, this research identifies three privacy and three surveillance frames. The analysis shows what frames are used by the grand coalition as well as the opposition in the Bundestag, and which have the most influence on the legislative outcome. As a result, this study reveals the goals German politicians pursue in relation to privacy and surveillance. One of the main findings is that privacy is discussed less often than surveillance, and is mainly presented in relation to personal data. The dominant privacy frame represents privacy as threatened by the flawed technologies and unsecure data sharing practices. Another important finding is that the grand coalition considers freedoms and security as conflicting rights, which should be brought into balance. As evidence of this approach, one of the surveillance frames interprets surveillance as a democratic response to security issues. However, the dominant surveillance frame portrays surveillance as an excessive practice of national secret services. The most remarkable finding is the shift that occurred between the moment of Snowden's revelations about the USA's global surveillance practices in the beginning of 2014, and the attack on Charlie Hebdo in January 2015. Whereas surveillance was initially seen as an antidemocratic practice of foreign secret services, it rapidly turned into an acceptable tool ensuring security and preventing terrorism.
\end{abstract}

\section{Introduction}

In 2013, Edward Snowden revealed shocking details on the National Security Agency's (NSA) global practices of mass surveillance. It appeared to be the tip of the iceberg of surveillance practices carried out by the state and private actors pursuing their political and commercial interests. However, despite growing interference in privacy worldwide, the evaluation of surveillance varies in different countries, and demonstrates significant variations in view of "what privacy is, why it might be important and whether it may have to be 'traded' for more security at certain times of crisis" (Lyon, 2015, p. 261).

Therefore, it is particularly necessary to look into how the European Union (EU) member states deal with issues of privacy and surveillance in practice, especially in light of the security threats due to terror attacks across Europe. The official position of the EU concerning security and privacy is to respect both fundamental human rights equally (Barnard-Wills, 2013, p. 175). Thus, according to the EU, privacy and security present complementary rights, which should not contradict each other. However, following the 2016 Berlin terror attack, the German government pushed through unprecedented measures of mass surveillance, such as video monitoring of public places (Chase, 2017; Lubin, 2017). This resulted in extensive public criticism due to the privacy violations caused by these measures. The government argued that the main goal of extending surveillance measures was to ensure better security and prevent terrorism. But how are these measures compatible with the right to privacy as defined in EU law? Is Germany becoming an Orwellian surveillance state?

1 Iana Gein received a bachelor degree in European Studies at Maastricht University. Contact: $\underline{\text { i.gein@student.maastrichtuniversity.nl }}$ 
Previous studies have not sufficiently examined how politicians present issues related to privacy and surveillance in their rhetoric. Scholars who study privacy and surveillance agree on the idea that surveillance violates privacy (Bauman et al., 2014; Edgar, 2017; Lyon, 2015). However, they are primarily concerned with clarifying definitions of these phenomena and studying the relations between them, such as whether privacy can or cannot be an antidote to surveillance (Bennet, 2011, p. 493; Lyon, 2015, p. 259; Stalder, 2002, p. 120). Thus, they do not look into how political actors present privacy and surveillance in their political rhetoric and what goals they are trying to achieve by this.

In order to expand our understanding and reveal the goals of politicians, this paper investigates how privacy and surveillance are portrayed in the political discourse of Germany, which is one of the leading EU member states. It does so by studying how members of the Bundestag frame issues related to privacy and surveillance in political debates. This analysis is focused on framing, a rhetoric tool, which can be used to highlight certain attributes of an issue and, as a consequence, achieve a favourable response to a problem (Entman, 1993; Hallahan, 2008). Therefore, this study will elaborate the different articulation and representations of the issues related to privacy and surveillance in the Bundestag debates. As a result, the analysis reveals which political goals Bundestag members pursue in relation to privacy and surveillance.

The framing analysis is based on the definition given by Entman, who argues that a frame consists of selected "aspects of a perceived reality and make them more salient in a communicating text, in such a way as to promote a particular problem definition, causal interpretation, moral evaluation, and/or treatment recommendation for the item described" (1993, p. 52). Privacy and surveillance frames are identified in the Bundestag parliamentary protocols using the inductive method. Compared to the deductive approach, which is limited to the already established frames, the inductive method makes it possible to identify new frames, which have not been established yet (Matthes \& Kohring, 2008). The methodology of the framing analysis will be guided by the approach developed by Matthes and Kohring (2008). This methodology improves reliability and validity, and, as a result, ensures the quality of this research.

This paper is guided by the following research question: comparing the framing of privacy and surveillance, what are the frames, and how did they evolve in the Bundestag political debates in the period between 2014 and 2017? The time period of the study starts after Snowden's revelations and includes security threats such as terror attacks. My claim is that terrors attacks in Europe and especially in Germany have deeply affected the representation of surveillance and privacy frames in the Bundestag debates. Germany is chosen for this study as the most populated European state and the largest economy of the EU, which makes it politically influential. Therefore, this research will contribute to our understanding of political processes in Europe in relation to privacy and surveillance.

To address the issues of privacy and surveillance in political rhetoric, this paper starts with a review of academic debates on privacy and surveillance. After highlighting the most relevant ideas, it elaborates on the framing analysis and explains this study's methodology. Paving the way for the analysis, Chapter 4 identifies privacy and surveillance frames using the inductive method, before scrutinising the identified frames and explaining their developments through time. This study ends with a conclusion that summarizes the findings and outlines the implications of how members of the Bundestag present privacy and surveillance in their rhetoric.

\footnotetext{
$2 \mid$\begin{tabular}{l|l} 
Marble \\
Research \\
Papers
\end{tabular}
} 


\section{Academic debates on privacy and surveillance}

The analysis presented in this paper would not be effective without first outlining the relevant academic debates. Issues relating to privacy and surveillance have been studied by various authors (BarnardWills, 2013; Bennett, 2011; Edgar, 2017; van Dijck, 2014; Friedewald et al., 2013; Lyon, 2015; Raley, 2013; Stalder, 2002; Taylor, 2017). Nevertheless, despite the attention, the concept of privacy has differing meanings and lacks a clear definition (Barnard-Wills, 2013, p. 170). Moreover, the connections between the interrelated fields of privacy and surveillance remain uncertain and even puzzling. Hence, in order to refine the knowledge on privacy and surveillance and to create a basis for further analysis, this chapter examines the current academic debates on privacy and surveillance.

Privacy is understood as a right and a civil liberty that constitutes the basic democratic right of a free citizen (Lyon, 2015, p. 253). As a fundamental right, privacy is protected by policy documents such as the Universal Declaration of Human Rights (1948) and the Charter of Fundamental Rights of the European Union (2000). The roots of privacy as an idea can be found in liberal individualism, which assumes differentiation between a civil society and a state (Bennett, 2011). Hence, privacy means separation and protection of "the self" from any form of external intervention (Bennett, 2011, p. 486). In this sense, privacy is a civil liberty, which distinguishes a free individual and is correlated with a "decent human life" (Lyon, 2015, p. 269).

Despite its recognised value, a number of scholars share the opinion that privacy is a slippery concept that is difficult to define (Bennett, 2011; Friedewald et al., 2013; Stalder, 2002). One of the main issues with the interpretation of privacy was noted by Stalder, who points out the flaws of presenting privacy as a "bubble that surrounds each person" (2002, p. 121). In this definition, privacy is equated with a physical space under the exclusive control of an individual. Stalder believes that such a conceptualisation is inadequate today due to the emergence of surveillance technologies, such as video surveillance of public places and by using telecommunication technologies (2002, p. 121). Moreover, by framing the privacy problem as "my home is my castle," a range of privacy related issues are left out of the scope of attention. Therefore, the conceptualisation of privacy as restricted to a physical space under the exclusive control of an individual implies radical limitations that might bear undesirable political and social consequences. For example, spheres that do not imply the physical presence of an individual, such as the privacy of personal data and communication, are not included in this simplistic definition.

In order to better understand the complexity of privacy as a phenomenon and define its scope as a concept, Friedewald et al. (2013) outline seven types of privacy, which include privacy of the person, behaviour and action, communication, data and image, thoughts and feelings, location and space, and privacy of association. Based on this definition, it can be concluded that surveillance can interfere in all private spheres by means of collecting information about the person's characteristics, behaviour, communication, personal data, thoughts, locations, and other activities. As a consequence, surveillance violates privacy and threatens this basic democratic value.

Scholars argue that despite its "slipperiness" (Bennett 2011, p. 493) the concept of privacy can help to address issues of governmental practices such as surveillance (Bennett, 2011; Lyon, 2015; Stalder, 2002). Furthermore, Lyon argues that privacy presents a concept, which helps to understand why mass surveillance is a threat to democracy (2015, p. 240). In a similar vein, Bennett considers privacy as a tool to frame governmental practices, such as surveillance (2011, p. 486). Hence, privacy presents a concept that helps to understand an impact of surveillance. Although Bennett points out that 
privacy is not an "antidote to surveillance," he acknowledges that privacy frames political and social discourses over surveillance (2011, p. 493). This argument demonstrates a strong connection between these two concepts.

Compared to privacy, the concept of surveillance does not attract as much disputes over its conceptual meaning, and is defined as the "garnering of personal data for detailed analysis" (Lyon, 2003 , p. 1). Lyon outlines three dimensions of surveillance, which are differentiated based on the actors carrying it out: the governmental, corporate, and civil dimension (2015, p. 37). Gathering personal data by these actors can take different forms, such as video and Closed Circuit Television surveillance, surveillance on the Internet, or surveillance by using telecommunication means. In the age of advanced technologies, much attention has been given to dataveillance, which is a new form of surveillance that uses data and metadata (van Dijck, 2014; Raley, 2013; Taylor, 2017).

Lyon points out that security presents the main driver of surveillance (2015, p. 89). Like privacy, security is a fundamental right, which is legally protected by the EU and the Universal Declaration of Human Rights (1948). Security is seen as necessary to protect "democracy, fundamental rights and freedoms of citizens, and to assert national identity" (Barnard-Wills, 2013, p. 172). The official position of the EU declares privacy and security as equal and complementary rights (BarnardWills, 2013, p. 175). However, attempts to balance these rights can be found across German policy documents (Barnard-Wills, 2013). German political discourse presents surveillance as a norm that is required to ensure security (Bundestag, 2017), supporting Lyon's argument. In a situation of security risks due to terror attacks, attempts to ensure national security by surveillance can lead to violation of the right to privacy.

Nevertheless, in German policy documents, surveillance is not clearly defined as a threat to privacy (Barnard-Wills, 2013). Barnard-Wills argues that in Germany, threats to privacy come from "police, intelligence agencies, and the risks of sharing data with the United States" (2013, p. 176). Moreover, threats to privacy and personal data protection are often presented as a consequence of flawed information technologies and unsafe data sharing practices, rather than coming from "surveillance" as a phenomenon (Barnard-Wills, 2013, p. 176). Therefore, discussions on privacy can drift to how to keep personal data safe, but not how to restrain surveillance as a practice. As an evidence of this tendency, Bennett points out that contemporary legislation regarding information privacy and personal data is mainly concerned with issues on how to manage data processing rather than limiting it (2011, p. 494).

The review of the literature presented in this chapter is relevant for this study because it provides an overview of the scope and relations between the concepts of privacy and surveillance. In addition, it gives an understanding of the role of security as the driver of surveillance, and how governments understand and deal with issues related to privacy and surveillance. In particular, the literature review demonstrates that Germany tends to balance the right to privacy and the need for surveillance. Furthermore, according to Barnard-Wills, threats to privacy in German policy documents are seen as coming from police, intelligence agencies, and data sharing practices (2013, p. 176). These findings will be compared with the results of the inductive frame identification in the Bundestag debates in Chapter 4. As a result, the research adds to our understanding of how Bundestag members present issues related to privacy and surveillance.

\footnotetext{
4 \begin{tabular}{l|l} 
Marble \\
Research \\
Papers
\end{tabular}
} 


\section{Framing}

Before addressing the research question, it is necessary to elaborate on the design of the analysis and clarify the methodology of this study. In order to investigate the representation of privacy and surveillance in the Bundestag's political discourse, this study adopts the framing analysis as outlined by Entman (1993) and Rein and Schön (1991). This chapter begins with an explanation of the role of framing. Following from this, Chapter 4 outlines the method of the study.

Rein and Schön (1991) define framing as a "way of selecting, organising, interpreting, and making sense of a complex reality so as to provide guideposts for knowing, analysing, persuading, and acting. A frame is a perspective from which an amorphous, ill-defined problematic situation can be made sense of and acted upon" (p. 263). Gamson and Modigliani (1989) describe framing as a "central organizing idea or story line that provides meaning to an unfolding strip of events" (p. 143). Thus, a frame presents a narrative that makes an emphasis on particular aspects in order to provide reasoning and consequently encourage audiences to think and act in a particular way (Chong \& Druckman, 2007; Entman, 1993; Hallahan, 2008; Gross \& D'Ambrossio, 2004; Iyengar \& Simon, 1993; Van Gorp, 2010).

In this research, frames on surveillance and privacy are identified through inductive analysis that applies the definition of a frame as developed by Entman (1993). This definition contains a description of particular elements of a frame, which are helpful for frame identification with the inductive method. According to Entman, a frame embodies a selected silent representation of social reality and usually consists of four dimensions (1993, p. 52). The first dimension is problem definition, which determines a causal agent and its actions. Diagnosis of causes is the second element that identifies the forces, which created the issue at hand. Moral judgment, the third element, entails an evaluation of causal agents and their actions. Finally, remedies offer solutions for this issue and predict their effects. Entman points out that a frame might not necessarily include all four dimensions, while a single sentence can embody more than one function (1993, p. 52).

Based on the definitions of Entman (1993), Rein and Schön (1991), and Gamson and Modigliani (1989), framing presents a rhetorical tool that helps to construct social reality by shaping perceptions and providing context for understanding a problem (Hallahan, 2008). Furthermore, scholars such as Fischer (2003), Fitzpatrick (2005), Foucault (1984), Hallahan (2008), and Yanow (2000) highlight the role of communication in reality construction. Additionally, Entman argues that frames can influence the reaction of the audience by drawing attention to selected aspects while overshadowing other details (1993, p. 55). In light of this, framing is a crucial element of communication, which can be used by political actors in order to promote their goals by influencing the public opinion. For frames in political rhetoric, problem-setting narratives are fundamental as they "link causal accounts of policy problems to particular proposals for action" (Rein \& Schön, 1991, p. 263). Importantly, problem-setting narratives lead to the emergence of "different views of the world" and can create "multiple social realities" (Rein \& Schön, 1991, p. 264). In political discourse, this can refer to the competing views and perspectives of the politicians who present their visions regarding a certain topic.

Scholars recognise importance and implication of framing in political rhetoric (Callaghan \& Schnell, 2009; Daviter, 2007; Lee \& Chang, 2010; Price \& Tewksbury, 1997). Political actors aim to gain a desired feedback from the audience by drawing attention to particular aspects in communication, and limiting the scope of a situation or an argument (Hallahan, 2008, p. 1). This kind of framing, used to achieve a certain goal, is named "strategic framing" by Hallahan (2008, p. 1). In addition, framed 
messages from political elites have essential immediate impact (Druckman \& Nelson, 2003), and thus, by highlighting certain aspects in communication for a prolonged period, influence the normative understanding of reality. As a result, frames determine the audience's perception, evaluation, and even action regarding a particular issue (Entman, 1993; Hallahan, 2008).

Daviter (2007) points out that in political communication, framing is used not only in agenda setting, but also performs several functions in policymaking. Thus, it can be argued that framing is an influencing tool that "shapes the formation of substantive interests and at times restructures political constituencies" (Schmitter, 1992, p. 379). In addition, frames serve as narratives, and reflect goals and systems of beliefs of political actors (Rein \& Schön, 1991). Therefore, it is necessary to understand how Bundestag members frame issues related to privacy and surveillance in order to understand their goals in relation to privacy and surveillance. As a result, this study will provide insight on the possible consequences of such political rhetoric.

\section{Methodology}

Having outlined the concepts of privacy and surveillance and introduced the framing analysis, this chapter presents the methodology of the study by discussing the method of analysis and the ways to improve validity and reliability, sources, and case selection. At the end, the chapter clarifies how frames related to privacy and surveillance are identified.

Deductive and inductive methods are the two main methodological approaches to frame analysis. The deductive method derives the frames from the existing literature and then investigates the frequency with which frames occur in the studied sources by a quantitative content analysis (Matthes \& Kohring, 2008, p. 262; Touri \& Koteyko, 2015, p. 603). Therefore, such a study is limited to already established frames, which have to be identified before the analysis. As a consequence, this approach is unable to capture changes in framing and identifying new frames (Matthes \& Kohring, 2008, p. 275). This shortcoming can be tackled by the inductive method.

In this research, frames are identified based on the inductive framing methodology developed by Matthes and Kohring (2008). Like Entman (1993) the authors argue that a frame presents a combination of several elements. Matthes and Kohring (2008) suggest looking for single frame elements and identifying a frame in case these elements form a pattern that is found in several texts (Matthes \& Kohring, 2008, p. 263). Thus, this study looks into the four frame dimensions defined by Entman (1993) in the Bundestag parliamentary protocols in period between the beginning of 2014 and the end of 2017 and codes them.

A paragraph from a speech of a political actor that contains the keywords "Überwachung" (surveillance) or "Privatsphäre" (privacy) is taken as a unit of analysis. Every unit is studied using content analysis in order to identify elements related to the dimensions specified by Entman (1993) and coded using the software ATLAS.ti. As a result, a table with documents and codes is analysed in order to identify frames using cluster analysis (Matthes \& Kohring, 2008, p. 263). A task of clustering is to group frame elements in order to produce frames. As it was emphasised in the previous chapter, in policy debates, a frame presents a problem-setting narrative, therefore, the main focus lies on problem definition and solution detentions. In case a certain combination of these elements is found in more than two speeches it counts as a frame. After that, identified frames are examined over the studied period. As a result, this approach as developed by Matthes and Kohring (2008) improves this research's quality by

\footnotetext{
6 \begin{tabular}{l|l} 
Marble \\
Research \\
Papers
\end{tabular}
} 
eliminating threats to validity and reliability. First, the operationalisation of frame elements leads to a better understanding of the frame (Matthes \& Kohring, 2008, p. 275). Secondly, frames are empirically identified using the inductive clustering method. Therefore, the frames are not defined subjectively beforehand but emerge empirically from the analysis. As a consequence, this approach enables to identify and code frames in a valid and reliable way.

The empirical base of this research consists of Bundestag parliamentary protocols, which were collected from the Bundestag's official website (www.bundestag.de). The Bundestag is the German federal parliament and the highest institution in the legislative system. Plenary sessions of the Bundestag provide a forum for its members to engage in public debates. During these sessions, politicians present their ideas, discuss legislative initiatives, and debate political events. Every session of the Bundestag is recorded by stenographers and is then made publically available as a protocol. Therefore, parliamentary protocols are a significant source to learn about Bundestag members assert their ideas and frame the issues related to privacy and surveillance.

In the studied period, 242 parliamentary protocols were collected for further analysis. Every protocol was analysed in order to select the paragraphs that contain the keywords "Privatsphäre" and "Überwachung" for privacy and surveillance respectively. Among the 242 protocols, 46 contain 86 mentions of privacy, while 182 protocols mention surveillance 992 times. It must be noted that in German language, the term "Überwachung" also refers to monitoring, observation, or regular control. In order to exclude irrelevant documents, content analysis was performed. The content analysis allowed to exclude irrelevant documents on debates on market surveillance or surveillance in fields such as medicine, custom, or economics. As a result of the content analysis, 46 parliamentary protocols were selected for framing analysis on privacy. The second set consisted of 60 protocols for framing surveillance. The privacy and surveillance sets were treated separately.

\section{Analysis}

Having outlined the methodology, it is now possible to carry out the analysis. This chapter begins with an inductive framing analysis of Bundestag parliamentary protocols. By doing this, it responds to the first part of the research question and reveals what frames related to privacy and surveillance can be identified in the studied period. The next section addresses the development of the privacy and surveillance frames in detail. Inspection of the shifts and developments allows to answer the second part of the research question, how these frames evolved in the political discourse of the Bundestag. All this meets the aim of this research to understand how Bundestag politicians present issues related to privacy and surveillance.

\section{$5.1 \quad$ Inductive framing}

This analysis was guided by the frame definition of Entman (1993) and methodology of the inductive frame identification of Matthes and Kohring (2008). Inductive clustering identified three frames related to privacy and three to surveillance. Using a keyword search, every unit of analysis was investigated and coded based on Entman's (1993) definition of the four frame dimensions. The establishment of a frame was based on the identification of a combination of the same codes for problem definition, causal interpretation, evaluation, and suggested remedy that is found in more than two speeches. It must be 
noted that different political actors can use the same frame as a narrative in their rhetoric (Van Gorp, 2005). Therefore, the codes also included information regarding speaker's political party affiliation in order to assess the possible implications of the studied debates for German society, since the coalition of CDU/CSU and SPD has a significant influence over the legislative outcome compared with other political parties.

The analysis of the parliamentary protocols identified that privacy is primarily seen as a right and a democratic value, which is threatened by different forces and, therefore, has to be protected. The majority of the codes refer to the problem definition and the possible remedies, which corresponds with the frame vision of Matthes and Kohring (2008). Problem definition specifies particular issues that threaten privacy. Among them are surveillance by foreign agencies, such as the National Security Agency (NSA), and national agencies, such as the Bundesnachrichtendienst (BND), espionage, new technologies allowing advanced means to gather information, and legislative initiatives that expand surveillance measures. Solutions aim to protect privacy and balance it with the needs of national security. As a result of the cluster analysis, three frames related to privacy were identified, which are presented in Table 1.

Table 1: Compilation of privacy frames

\begin{tabular}{|c|c|c|c|}
\hline Frame elements & P1. Surveillance & P2. Digital challenges & P3. Legislative initiatives \\
\hline 1. Problem definition & $\begin{array}{l}\text { International information } \\
\text { agencies, such as the NSA, } \\
\text { gather information on } \\
\text { German citizens, including } \\
\text { top politicians. }\end{array}$ & $\begin{array}{l}\text { Modern means of } \\
\text { communication are not safe } \\
\text { enough to keep, process, and } \\
\text { transfer personal data. }\end{array}$ & $\begin{array}{l}\text { Bundestag members from } \\
\text { CDU/CSU and SPD expand } \\
\text { survey authority and extend } \\
\text { surveillance practices of } \\
\text { national services, such as } \\
\text { the BND. }\end{array}$ \\
\hline 2. Causal attribution & $\begin{array}{l}\text { Information about German } \\
\text { citizens can bring benefits } \\
\text { in political and economic } \\
\text { fields. }\end{array}$ & $\begin{array}{l}\text { New communication } \\
\text { technologies provide advanced } \\
\text { means to gather and process } \\
\text { personal information. } \\
\text { Additionally, they are not well } \\
\text { secured from illegal } \\
\text { surveillance. }\end{array}$ & $\begin{array}{l}\text { New surveillance measures } \\
\text { are necessary to prevent and } \\
\text { fight terrorism and crime, } \\
\text { and, thus, ensure national } \\
\text { security. }\end{array}$ \\
\hline 3. Moral evaluation & $\begin{array}{l}\text { Practices of information } \\
\text { secret services infringe } \\
\text { democratic principles, and } \\
\text { violate privacy. }\end{array}$ & $\begin{array}{l}\text { Digital practices of mass } \\
\text { surveillance gather and } \\
\text { process personal data and, by } \\
\text { doing this, violate privacy. }\end{array}$ & $\begin{array}{l}\text { Surveillance is an excessive } \\
\text { measure that violates } \\
\text { privacy and does not lead to } \\
\text { better civil protection. }\end{array}$ \\
\hline 4. Solution & $\begin{array}{l}\text { Privacy is a basic right; } \\
\text { therefore, it should be } \\
\text { protected and balanced } \\
\text { with security measures. }\end{array}$ & $\begin{array}{l}\text { New legislative measures to } \\
\text { protect personal data and } \\
\text { privacy; investments in IT } \\
\text { security. }\end{array}$ & $\begin{array}{l}\text { Current surveillance is } \\
\text { sufficient; the legal } \\
\text { initiatives aiming to expand } \\
\text { survey authority should not } \\
\text { be adopted. }\end{array}$ \\
\hline $\begin{array}{l}\text { Political affiliation of } \\
\text { the actors, which } \\
\text { use this frame }\end{array}$ & $\begin{array}{l}\text { CDU/CSU, SPD, the Green } \\
\text { Party, the Left Party }\end{array}$ & $\begin{array}{l}\text { CDU/CSU, SPD, the Green } \\
\text { Party, the Left Party }\end{array}$ & $\begin{array}{l}\text { The Green Party, the Left } \\
\text { Party }\end{array}$ \\
\hline
\end{tabular}

Source: Inductive framing analysis of the Bundestag protocols, 2014-2017

The first narrative, "Surveillance," frames privacy as a basic right, and as being threatened by espionage and mass surveillance by foreign agencies. The problem definition points out the information revealed by Snowden on mass surveillance practices of the NSA. The reason behind espionage is that information about German citizens presents value that can bring political and economic benefits. An example of such violations is the revealed evidence of the NSA tapping Merkel's private conversations (Plenarprotokoll $18 / 10$, p. 572). A solution to this problem is protecting privacy by preventing surveillance. However, privacy rights should also be balanced with measures to ensure national security.

\footnotetext{
$8 \mid$\begin{tabular}{l|l} 
Marble \\
Research
\end{tabular} Papers
} 
The second frame, "Digital threats," corresponds with the outlined debates on privacy in Chapter 1 . This narrative describes concerns regarding digital security of personal data in the age of advanced surveillance technologies, such as monitoring through telecommunication means. This frame differs from the first one in its particular focus on the protection of personal data. These concerns were raised because of modern technologies that provide new means to gather and process personal information. These practices are in breach of the law on personal data protection and privacy. A solution to this problem is to protect personal data by strengthening legislation on data storage, transmission, as well as processing, and investment in IT security.

The third frame, "Legislative initiatives," can also be tied to the concepts discussed in Chapter 1. This narrative comprises concerns that new surveillance measures aiming at raising security levels are in breach of privacy. Security issues are the main driver why the Bundestag members from CDU/CSU and SPD promote legislative initiatives to expand surveillance and argue that surveillance proliferation would increase efficiency of security agencies. However, the Bundestag opposition condemns surveillance as an excessive and inefficient measure that violates privacy. A solution proposed by the opposition is to protect privacy rights by declining these legislative initiatives that expand national surveillance authority.

Compared to privacy, surveillance was debated more often in the studied period. Similar to the debates on privacy, most attention was devoted to pointing out problems and possible solutions. In contrast to the privacy debates, Bundestag members have different views on how to assess surveillance. Surveillance is seen as a problem in two cases. First, when it is conducted by foreign secret services, which is illegal in Germany. Second, surveillance it is seen as an issue when is promoted as a measure to ensure national security. However, surveillance is also understood as a democratic tool to ensure better security and civil protection. In this case, it is perceived as an acceptable measure, which is compatible with democratic rights and freedoms. As a consequence, the possible solutions are also different. Politicians agree to fight surveillance carried out by foreign secret services; but when it comes to national security, there are Bundestag members who see surveillance as an opportunity to ensure better civil protection. Consequently, they promote the proliferation of surveillance activities run by national agencies. The identified surveillance frames are summarised in Table 2.

The first frame, "International surveillance," considers surveillance as a threat coming from foreign secret services. This narrative emerged in political debates thanks to Snowden, who revealed how US state secret services interfere in private life by surveillance. The solution to this problem is seen in establishing a special committee that would monitor foreign surveillance activities, and initiate a dialogue with international partners to explain the German position on this matter. This should lead to the decrease of surveillance practices and, consequently, protect privacy.

Information on the NSA's global surveillance activities have also contributed to the discussion on the extent of German involvement in such practices. This led to the emergence of the second frame, "National surveillance," in the political discourse of the Bundestag. Like the first frame, this frame considers surveillance as a threat and violation of human rights that comes from the German national services, such as the BND. Therefore, state authorities should clarify the scope of such practices they subject German citizens to, and reduce them if they are found to be excessive. Bundestag members who use this frame argue that such practices are failing to meet their declared goal of ensuring better civil protection. A solution to the problem of national surveillance is reducing surveillance measures and investing in resources that improve crime prevention. 
Table 2: Compilation of surveillance frames

\begin{tabular}{|c|c|c|c|}
\hline $\begin{array}{l}\text { Frame } \\
\text { elements }\end{array}$ & $\begin{array}{l}\text { S1. International } \\
\text { surveillance }\end{array}$ & $\begin{array}{l}\text { S2. National } \\
\text { surveillance }\end{array}$ & $\begin{array}{l}\text { S3. Surveillance for } \\
\text { security }\end{array}$ \\
\hline 1. Problem definition & $\begin{array}{l}\text { International secret } \\
\text { services, such as those of } \\
\text { the US, and the UK, gather } \\
\text { information on German } \\
\text { citizens. }\end{array}$ & $\begin{array}{l}\text { Excessive surveillance } \\
\text { measures of the German } \\
\text { national secret services, such } \\
\text { as video surveillance, data } \\
\text { retention. }\end{array}$ & $\begin{array}{l}\text { High level of criminality } \\
\text { and terror threats; } \\
\text { therefore, need for new } \\
\text { resources and measures to } \\
\text { ensure order. }\end{array}$ \\
\hline 2. Causal attribution & $\begin{array}{l}\text { Information on German } \\
\text { citizens can bring } \\
\text { significant economic and } \\
\text { political benefits. }\end{array}$ & $\begin{array}{l}\text { Political actors promote and } \\
\text { support surveillance measures } \\
\text { in order to ensure better } \\
\text { national security. }\end{array}$ & $\begin{array}{l}\text { Lack of resources and } \\
\text { inadequate work of the } \\
\text { services involved in } \\
\text { ensuring security and } \\
\text { fighting terror. }\end{array}$ \\
\hline 3. Moral evaluation & $\begin{array}{l}\text { These practices violate the } \\
\text { rights and freedoms of } \\
\text { German citizens, damage } \\
\text { international relation, and } \\
\text { economy. }\end{array}$ & $\begin{array}{l}\text { Surveillance fails to fight } \\
\text { terror, while the state } \\
\text { intervention violates the basic } \\
\text { rights and freedoms of the } \\
\text { citizens. }\end{array}$ & $\begin{array}{l}\text { Surveillance is an } \\
\text { acceptable measure that } \\
\text { does not contradict } \\
\text { democratic rights and } \\
\text { freedoms. }\end{array}$ \\
\hline 4. Solution & $\begin{array}{l}\text { Review of the practices of } \\
\text { the international agencies } \\
\text { by a special committee, } \\
\text { dialogue with the partners } \\
\text { to clarify the German } \\
\text { position on this issue. }\end{array}$ & $\begin{array}{l}\text { Clarify the scope of the } \\
\text { current surveillance practices; } \\
\text { stop state surveillance } \\
\text { proliferation; apply more } \\
\text { resources to prevent crimes } \\
\text { instead of mass surveillance. }\end{array}$ & $\begin{array}{l}\text { More surveillance is } \\
\text { necessary in order to } \\
\text { ensure better security and } \\
\text { civil protection. }\end{array}$ \\
\hline $\begin{array}{l}\text { Political affiliation of } \\
\text { the actors, which use } \\
\text { this frame }\end{array}$ & $\begin{array}{l}\text { CDU/CSU, SPD, the Green } \\
\text { Party, the Left Party }\end{array}$ & $\begin{array}{l}\text { SPD, the Green Party, the Left } \\
\text { Party }\end{array}$ & CDU/CSU, SPD \\
\hline
\end{tabular}

Source: Inductive framing analysis of the Bundestag protocols, 2014-2017

On the contrary, the third frame, "Surveillance for security," considers surveillance conducted by German national authorities as an acceptable practice to prevent terror attacks and, thus, maintain better civil protection. In this narrative, a solution of the security problem is seen in the extension of survey authorities of the national services, such as the BND. Surveillance proliferation should help fight terrorism and criminality more efficiently. Moreover, surveillance is portrayed as a security measure in line with democratic standards.

\subsection{Examination of identified frames}

Having identified and presented the privacy and surveillance frames, this section provides their detailed inspection. The main focus of this section is the shifts in the development of the frames within the studied period and an explanation why the shifts occurred. Consequently, the section answers the research question of how the privacy and surveillance frames evolved in the Bundestag political discourse in the period between 2014 and 2017. Finally, the political goals of the Bundestag members in relation to privacy and surveillance are revealed.

The distribution of the privacy frames over the studied period can be seen in Figure 1. As was outlined in the previous section, Bundestag members understand privacy as a right that is threatened and, therefore, needs to be protected. The dominant frame is the digital challenges (P2), which appears more often compared with the other two narratives. However, foreign surveillance threats (P1) were debated more intensively in the beginning of the studied period. In contrast, threats to privacy caused by new surveillance measures (P3) constitute the weakest frame, which emerges at the end of the observed period.

\section{$10 \mid$\begin{tabular}{l|l} 
Marble \\
Research \\
Papers
\end{tabular}}


Figure 1: Distribution of the privacy frames

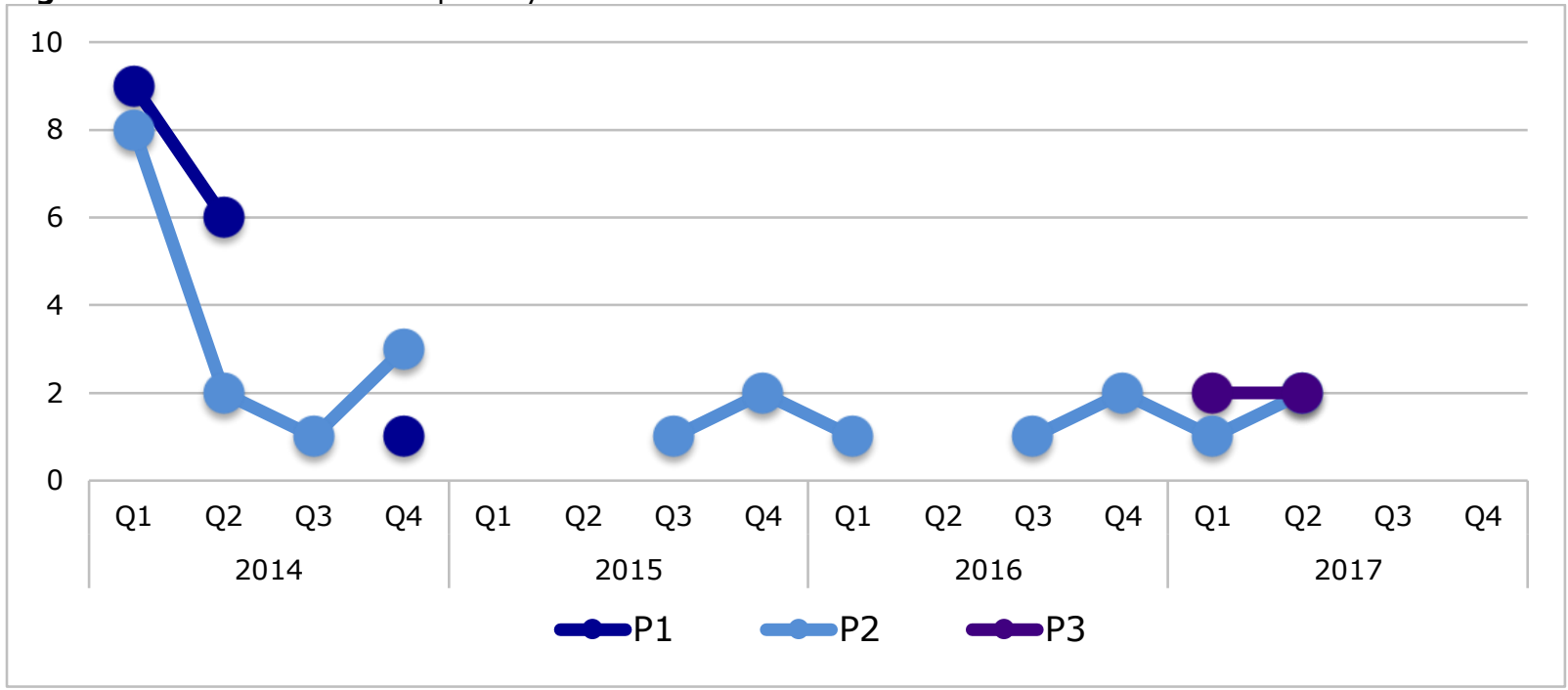

Source: Analysis of the privacy frames, number of times frames are identified in the Bundestag protocols within the studied period of 2014-2017

The surveillance practices of the NSA revealed by Snowden in 2013 were the main trigger for the first privacy frame (P1). The "Surveillance" privacy frame was intensely used in the Bundestag in the beginning of 2014. This narrative was identified in rhetoric of the main political forces, such as CDU/CSU, SPD, the Left Party, and the Green Party, with exception of AFD and FDP, which entered the Bundestag at the end of 2017. Bundestag members condemn foreign surveillance practices as violating privacy as a basic human right. In order to protect privacy, they call for establishing a special Committee to clarify the extent of the surveillance activities by foreign information agencies and to communicate the German position to the international partners. However, this frame has a short lifetime and disappears from political rhetoric after 2014. Intriguingly in this frame, when talking about privacy protection, German Chancellor Angela Merkel points out the need to balance privacy with the national security needs (Plenarprotokoll 18/10, p. 569). The Chancellor's position contradicts EU regulations, where privacy and security are defined as equal fundamental rights, which should be respected rather than balanced (Barnard-Wills, 2013, p. 175).

The idea of balancing privacy and security presented by Angela Merkel reflects a trade-off model between privacy and security. This model suggests that citizens would willingly trade their privacy for better security and civil protection. Yet, several scholars have challenged this and presented strong evidence against the validity of the trade-off model between security and privacy (Friedewald, Lieshout, Rung, Ooms, \& Ypma, 2015). In particularly, a pan-European survey indicated that there is no direct correlation between security and privacy attitudes (Friedewald et al., 2015).

Notably, the second frame (P2) is also related to espionage, however, it is focused on the security of telecommunication technologies and personal data protection. The "Digital challenges" narrative frames privacy as a right that is threatened by unsafe digital technologies, which can be used by foreign agencies in order to gather users' personal information. This frame is the leading frame, which supports the idea discussed in Chapter 1 that threats to privacy are seen mainly as coming from flawed technologies and insecure data sharing (Barnard-Wills, 2013, p. 176). Gregor Gysi, a member of 
the Bundestag from the Left Party, argues that 80 per cent of telecommunication data had been gathered by foreign secret services (Plenarprotokoll 18/10, p. 571).

Thus, the second privacy frame refers to the phenomenon of "dataveillance," which is a form of surveillance using data and metadata (van Dijck, 2014; Raley, 2013; Taylor, 2017). Taking into account that German legislation has a long history of protecting personal data, personal data privacy is a recognised right and is legally protected. Significantly, the right to informational self-determination ("Recht auf informationelle Selbstbestimmung") was already defined by the German constitutional ruling in 1983, years before it became official in the Charter of Fundamental Rights of the European Union (2000). Therefore, this can explain the focus on privacy as personal data, which is the dominant presentation of privacy in the Bundestag.

Remarkably, the first two frames are used by the main political forces of the Bundestag, except AFD and FDP that entered the Bundestag at the end of 2017. Only the opposition, the Left Party and the Green Party, use the third frame. The third privacy frame, "Legislative initiatives," argues against extension of the surveillance measures. This is the weakest narrative that appeared as a response to new surveillance initiatives following the December 2016 Berlin terror attack. The grand coalition of CDU/CSU and SPD introduced several legislative initiatives, such as video surveillance of public places and public transport networks, which should ensure security. Thus, security issues are the main driver of surveillance proliferation, which fits the argumentation of Lyon (2015, p. 89). The opposition criticizes these initiatives as being inefficient to prevent crimes and as breaching privacy. However, its political power is not sufficient to affect the legislative outcome.

Hence, two major events influencing political discourse over privacy and its framing can be defined. First, the revelations about the USA's global surveillance practices, and second, the 2016 Berlin terror attack. Based in Figure 2, which presents an overview of the distribution of surveillance frames in the studied period, it is evident that the discourse on surveillance has also responded to these events.

Above all, as visible on Figures 1 and 2, issues related to surveillance are debated more often than those related to privacy. The dominant surveillance frame is national surveillance (S2) which appears 67 times in the Bundestag debates. In contrasts, the most popular privacy frame, "Digital challenges," is identified 24 times. The other two surveillance frames are represented almost equally, 47 and 46 times respectively. Beginning of 2014, the most popular frame refers to surveillance as a threat coming from foreign security services (S1). At the end of the studied period, the most outstanding frame is national surveillance aimed to maintain security (S3). Thus, we can observe a turning point in the debates on surveillance during the studied period. Based on this, it can be concluded that the terror attacks changed the perception of surveillance. After Snowden's revelations, surveillance was considered an unacceptable (S1) or questionable (S2) measure. However, at the end of the studied period, surveillance is perceived a democratic solution to ensure national security (S3).

In political debates of the Bundestag, the first surveillance narrative emerged as a consequence of the information about US global surveillance revealed by Snowden in 2013. This frame discusses international espionage as a threat to democratic freedoms (S1) and can be compared with the privacy frame that condemns surveillance carried out by foreign secret services (P1).

\footnotetext{
$12 \mid \begin{aligned} & \text { Marble } \\ & \text { Research } \\ & \text { Papers }\end{aligned}$
} 
Figure 2: Distribution of the surveillance frames

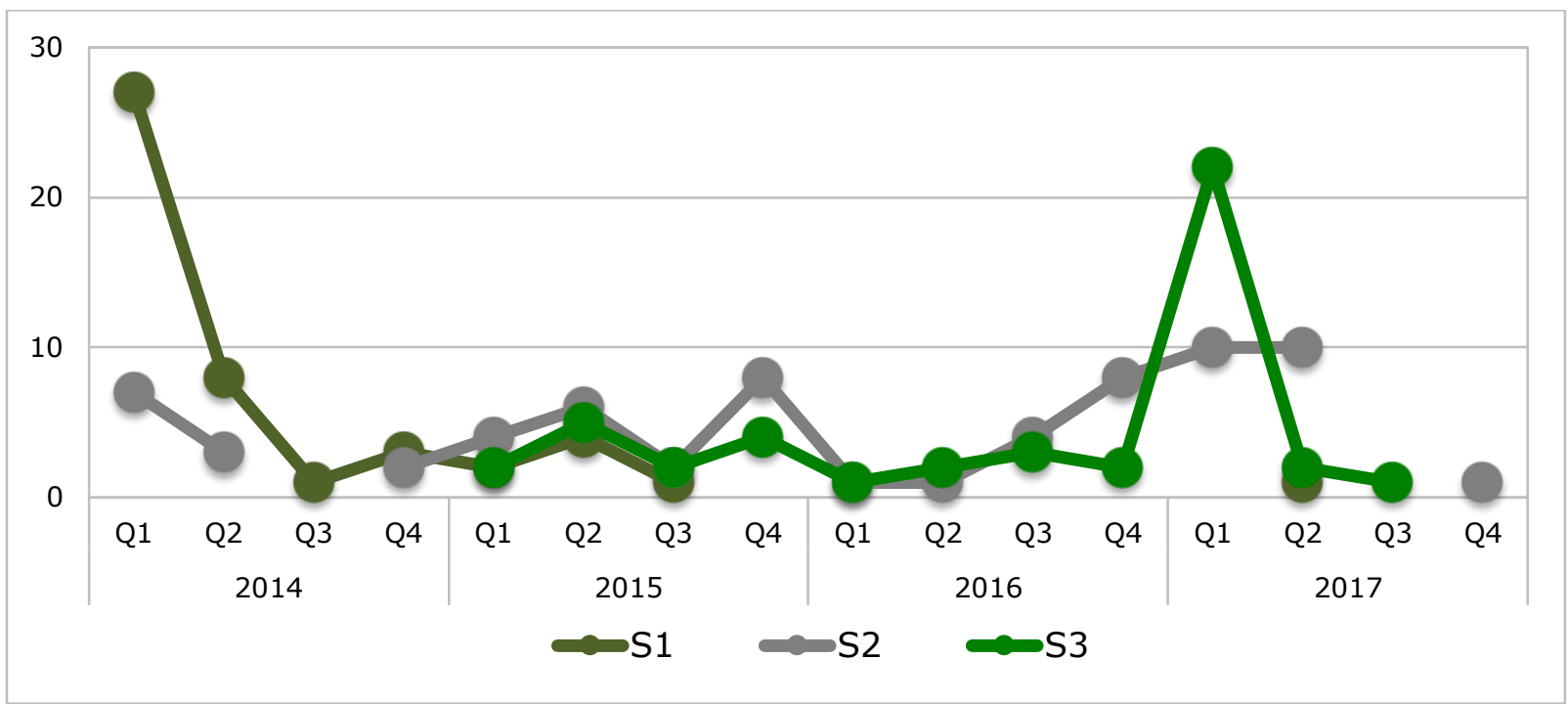

Source: Analysis of surveillance frames, number of times frames are identified in the Bundestag protocols within the studied period of 2014-2017

However, this surveillance frame does not have a particular focus on privacy issues. Instead, it discusses in general the violation of the democratic principles along with political and economic implications as a result of international espionage. Despite support of all Bundestag political groups at that time, this frame had a short lifetime compared with the others and disappeared in 2015. It was raised again in 2017 by the Green Party who tried to draw attention to this problem, which, according to the opposition, had not been solved.

Like the first narrative of surveillance, the second also condemns surveillance. However, this frame focuses on the practices of German national authorities (S2). Information about US surveillance has drawn attention to the activities of German secret services. This frame was identified not only in the rhetoric of the opposition, but also in one of the parties from the grand coalition. In 2015, SPD speakers condemned surveillance as an excessive measure that fails to prevent terror and reduce criminality: Lothar Binding and Svenja Stadler pointed out France, which failed to prevent the terror attack in January 2015 despite advanced surveillance measures (Plenarprotokoll 18/131, p. 12826). Based on this, the SPD speakers believe that data retention as one of the surveillance measures would threaten the well-being of German citizens to a greater extent than terrorist threats. However, this is the only case SPD politicians used this narrative.

In contrast to the first and the second surveillance frames, the third narrative does not condemn surveillance but frames surveillance as a necessary measure, which helps to ensure better civil protection. This frame (S3) first appeared in the beginning 2015 as a response to the Paris terror attack on Charlie Hebdo in January 2015 and reached its peak after the Berlin terror attack in December 2016. This narrative was used by the grand coalition of CDU/CSU and SPD that explained the necessity of measures, such as video surveillance of public places and retention of telecommunication data, by the national security needs. Importantly, this frame was also used in the rhetoric of Angela Merkel, who points out the need to introduce surveillance of Internet communication in order to prevent security 
threats, such as the attack in Paris in 2015 (Plenarprotokoll 18/139, p. 13610). Thus, the top German politicians and the grand coalition promote the idea of a balance between freedoms and security. This vision of balancing privacy and security corresponded with the privacy frame (P1), where the Chancellor of Germany also clarified her vision on security and freedoms, such as privacy rights.

To respond to critics, the federal minister of Internal Affairs Thomas de Maizière pointed out that introduction of new surveillance laws has nothing to do with the total control that is pictured by Orwell's novel "1984." According to de Maizière these measures are the reasonable extension of video surveillance aimed to ensure civil protection (Plenarprotokoll 18/216, p. 21649). Therefore, it is evident that the grand coalition of the Bundestag, which has direct influence on the legislative outcome, understands surveillance as a reasonable tool, which is seen as democratic and able to help achieving better civil protection by fighting crime and terrorism. Moreover, the active use of this framing promotes surveillance proliferation in Germany. Based on these facts we can anticipate a further expansion of surveillance in case of security threats, and further balancing of privacy with security measures.

\section{Conclusion}

This study investigated the framing of privacy and surveillance in Bundestag debates between the beginning of 2014 and the end of 2017. In doing so, the goals of the Bundestag politicians in relation to privacy and surveillance were revealed. In the age of growing surveillance technologies, it is important to understand how politicians understand privacy and surveillance and what role these phenomena play in today's politics. Germany is the biggest EU state with a considerable political weight; therefore, the results of this study can be used to assess the tendencies in European politics.

The study is limited to the Bundestag debates. However, the Bundestag is the highest legislative body, directly responsible for policy outcomes in Germany. The analysis has differentiated multiple frames, which were used by Bundestag members to justify legislation on privacy and surveillance matters. Therefore, the analysis has demonstrated what frames are used by the coalition, which has the most influence on the legislative outcome, as well as the opposition. Based on the outcomes of the analysis, we can anticipate policy changes in the spheres of privacy and surveillance, and, consequently, changes in German society.

As a result of inductive framing analysis, this research identified three privacy and three surveillance frames. The frames were identified through an analysis of Bundestag parliamentary protocols using the method developed by Matthes and Kohring (2008). Importantly, framing analysis was not limited to a study of already defined frames, since inductive framing enables an analysis of the full scope of the issues related to privacy and surveillance in the political debates of the Bundestag. The main drivers in the debates on privacy and surveillance, as identified by this analysis, are the revelations of Snowden regarding the NSA's global surveillance practices and the terror attacks in France and Germany.

One of the main findings is that in the Bundestag, privacy is discussed less often than surveillance, and is mainly presented as personal data. In parliamentary debates, privacy is framed as a value that is threatened and, therefore, has to be protected. Threats to privacy, according to Bundestag members, come from espionage, digital technologies, and legislative initiatives that extend the surveillance authority of national services. The dominant privacy frame discusses privacy as threatened by the flawed technologies and unsecure data sharing practices. The fact that politicians discuss privacy

\footnotetext{
$14 \begin{aligned} & \text { Marble } \\ & \text { Research } \\ & \text { Papers }\end{aligned}$
} 
primarily in the digital context of data protection is evidence that privacy is seen as personal data. This opens a discussion how to protect personal data rather than limit surveillance practices of foreign and national agencies.

The second important finding relates to how German politicians consider relations between privacy and security. Particularly, the Federal Chancellor of Germany Angela Merkel considers freedoms and security as conflicting rights that should be brought into balance. Based on this, Bundestag politicians promote a trade-off between privacy and security, which, contradicts the official position of the EU on the equality of these rights. As evidence of this approach, one of the surveillance frames interprets surveillance as a democratic response to security issues.

The third finding is that the dominant surveillance frame portrays surveillance as an excessive practice of national secret services, such as the BND. However, primarily the opposition uses this frame and argues that surveillance is excessive and fails to fight crime and prevent terrorism. Therefore, according to the politicians who use this frame, the state's authority to surveil should be limited. However, the opposition has a limited effect on the legislative outcome. In contrast, the grand coalition of CDU/CSU and SPD use narratives that describe surveillance as a democratic tool, which is needed to ensure security.

The shift in how politicians portray surveillance is the final finding of this study. In the beginning of 2014, due to Snowden's revelations, surveillance was intensively discussed as an anti-democratic practice of foreign secret services. However, this frame had a relative short lifespan. Starting with 2016, surveillance is no longer portrayed as anti-democratic practice of foreign secret services. After the Charlie Hebdo attack in January 2015, Bundestag members presented surveillance as an acceptable democratic tool to ensure security and prevent terrorism. This frame reached its peak after the Berlin terror attack in December 2016 and was the most popular frame in 2017. Importantly, surveillance as a solution for security threats is promoted by the grand coalition of CDU/CSU and SPD. This coalition had a majority in the Bundestag in the studied period, as well as after the election held in 2017 with a mandate until 2021, and, therefore, has direct influence over legislative outcomes.

To sum up, thanks to Snowden we learned about mass surveillance carried out by the US. This caused a huge outcry not only in the media, but also in political debates, which condemned such practices as anti-democratic and violating privacy rights. However, this study indicates that even though Snowden's revelations raised public awareness of surveillance and privacy issues, security challenges dominate over privacy concerns in the political rhetoric. Thus, based on this analysis, we can expect the introduction of new surveillance measures in Germany, as response to security threats, such as terror and crime. 